\title{
Drying study on Bryophyllum pinnatum leaves powder and its fortification in food product
}

Shital R. Pawar and Surekha B. Dabhade

See end of the Paper for authors' affiliation

Correspondence to :

Shital R. Pawar Department of Agricultural Engineering, Maharashtra Institute of Technology, Aurangabad (M.S.) India Email : pshital4912@gmail. com
-Abstract : The Bryophyllum pinnatum is a medicinal plant. The family of Bryophyllum pinnatum is Crassulaceae. The native place of Bryophyllum pinnatum is Madagascar. In Bryophyllum pinnatum, number of bioactive component is present such as alkaloids, triterpenes, lipids, flavonoids, glycosides, bufadienolides, saponin, phenols, and organic acid. Bryophyllum pinnatum is a medicinal plant and used as a treat the number of diseases like anthelmintic, wound healing, antioxidant activity and anti- inflammatory, etc. Mostly Bryophyllum pinnatum leaves used to treat Urinary Tract Infection. This review studied on the nutritional composition of the Bryophyllum pinnatum leaves powder after drying and its fortification into food product. Bryophyllum pinnatum leaves is a good source of human nutrition and good dietary supplements. There are number of alternative drying methods will be used for the drying of the Bryophyllum pinnatum leaves instead of shade drying method. Alternative methods of drying are Microwave drying and tray drying. This drying will be carried out at different temperature for specific time period. The Bryophyllum pinnatum leaves powder is fortified into the different food product like,bakery, confectionary, extruded products, etc. This food product shows nutritional as well as medicinal values it is called as nutraceutical food. The main objective of this review is drying study on leaves, nutritional composition and its fortification in food product.

- Key words : Bryophyllum Leaves, Medicinal value, Nutritional composition, Drying methods

- How to cite this paper : Pawar, Shital R. and Dabhade, Surekha B. (2018). Drying study on Bryophyllum pinnatum leaves powder and its fortification in food product. Internat. J. Agric. Engg., 11(Sp. Issue) : 155-158, DOI: 10.15740/HAS/IJAE/11.Sp. Issue/155-158. 